\title{
Assessment of On-Grid and Off-Grid Electrification in Remote Villages of Chhattisgarh
}

\author{
Saurabh Pathak ${ }^{1,2 *}$ and Rajni Verma ${ }^{1,3}$ \\ ${ }^{1}$ School of Engineering, RMIT University, Australia \\ ${ }^{2}$ Department of Mechanical Engineering, University of Melbourne, Parkville, Australia \\ ${ }^{3}$ School of Physics, The University of Melbourne, Australia \\ *Corresponding author: School of Engineering, RMIT University, Department of Mechanical Engineering, University of Melbourne, \\ Parkville, VIC, 3010 Australia
}

\begin{abstract}
In this work, electrification scenario of the state of Chhattisgarh has been presented, which is the 10th largest state of India with a total population 25 million has total 19567 villages and $80 \%$ of the population lives in rural areas. Herein, we have bestowing 17 out of 133 villages in which electrification has been done in 2017 and 2018. All these villages are in the region Dantewada and Bijapur. These two regions consist most remote villages of the state and the awareness about, how electricity will help them in improving their lifestyle is quite less. The focus of the present work is aligned to investigate the electricity connectivity scenario of these remote villages. Further, alternative novel mechanism of the remote village electrification using magnetic fluid-based energy harvesting has been proposed which can eventually solves the major issues in remote village electrification.
\end{abstract}

\section{Introduction}

Electricity is one of the most basic need of the population in recent times and it significantly affects the quality of life. Electricity can transform the rural areas in many ways. Availability of electricity in rural areas will reduce the manual workload for food processing and longer working hours in the households, end of smoky households etc. It will yield direct positive impact at household, individual and community level. Electrifying a remote village household can significantly lower the energy expenditures made on kerosene and fuels which can be substituted by straight electricity admittance. Further, it provides the family living in the household with more working time that eventually fallouts in improving the overall quality of life and productivity of each household [1]. Although, the casual relationship between the electricity and quality of life has not been laid down, but it has been long argued based on the available literature that it significantly affects the quality of life both economically and productivity wise. So, the focused my present work is to understand the effect of electrification on the ruler masses of the Chhattisgarh. We have surveyed 17 villages in remote areas of Chhattisgarh by visiting 3 villages Dhanora, Gampur and Pinkonda in person and in rest of the 14 villages by contacting the school teachers and local peoples through telephonic conversation. So, this work explains in detail the current situation of these villages how solar power in the villages is improved and further discuss the possibility of low maintenance wind energy to meet the off-grid requirement for these village [2, 3].

Alternatively, another possible solution to meet the need of the country is through wind energy. We have developed a magnetic fluid-based power generator which is capable of working at low wind speed and has the potential for meeting the need of the small electricity loads in the villages. This device can generate enough electricity for a small household needs. In all, the overall aim to analyze the importance of electricity and its impact on the livelihood of the households has been done satisfactory in these villages. Magnetic fluid-based energy generator has the potential to provide the solution to the current electrification needs of the remote villages in India [4-9]. 


\section{Consequences of Lower Livelihood Opportunities in Rural Areas}

The growth of the population in Chhattisgarh's rural areas has declined drastically in the last two decades. Bijapur and Dantewada are the two major regions of Chhattisgarh which has evident the most seaver effects of these problems. The major reason contributing to this decrease is attributed by the expert is, decrease in livelihood opportunities of the tribes due to deforestation. In Chhattisgarh, eleven regions of the state are fully or partially affected by decrease in population. The population growth rate of these eleven districts from 1991 to 2011 have been shown in Figure 1. We can clearly see from the Figure 1 that population growth in these regions has decreased very sharply. The maximum fall in the population growth rate has been observed by the regions Bijapur, and Korea. To rehabilitate tribal population back to their home, more and more livelihood opportunities such as employment, water, connectivity, electricity, better homes and basics amenities, needs to be created in these regions. Electrification is one of the major areas in these regions to boost the livelihood opportunities and uplift the living standards of the tribes $[10,11]$.

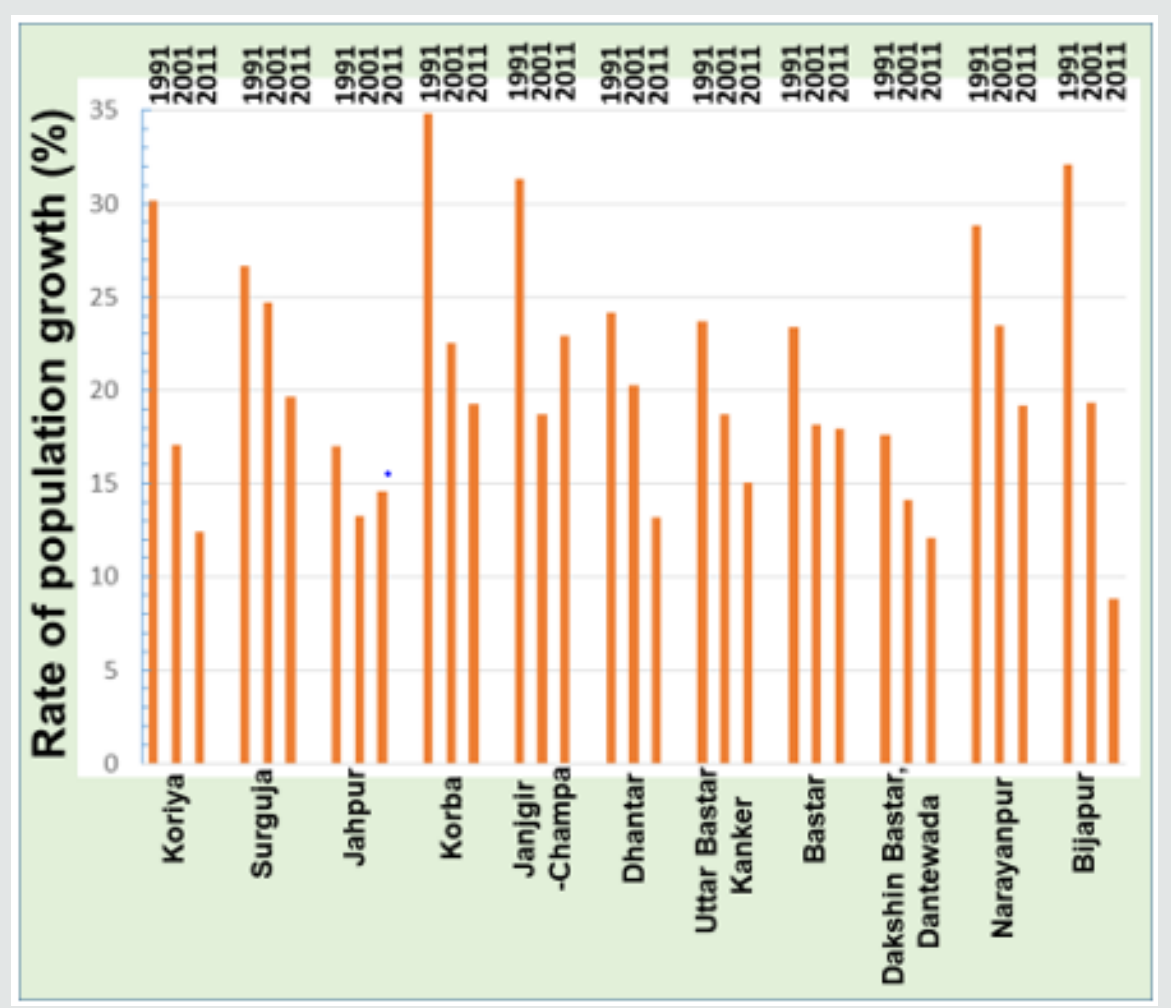

Figure 1: Rate of population growth in Chhattisgarh eleven districts from 1991 to 2011.

\section{Renewable Energy in Chhattisgarh}

Chhattisgarh is tried, tested and proved solar microgrids to be the most successful means of remote area electrification. The small state of Chhattisgarh which is very rich in minerals is covered in almost $43 \%$ by the forest and safety apprehensions avert grid electrification. This made it ideal for the authorities to explore solar photo voltaic (PV) technology since the Electricity Act 2003 allows distribution of electricity in villages without formal permission of State Electricity Boards. The state agency, CREDA obtained the list of un-electrified villages from Chhattisgarh State Electricity Board and installed standalone solar home lighting systems in 500 villages through 100 per cent subsidy program. The system comprised of PV modules, cables, an inverter, a battery and two 11 Watt CFLs. CREDA has also explored alternative methods and finally opted for solar PV microgrids. The cost of setting up a microgrid (PV power system and transmission cables) per household is Rs $25,000 /-$ as against a home-lighting system that costs Rs 14,000/-. Although a microgrid is costlier compared to a home lighting system they prevent theft and require minimal maintenance, hence the capital funds invested is protected. Secondly, they increased the size of a single module from $50 \mathrm{Wp}$ to $75 \mathrm{Wp}$. Due to increased size and heavy it was virtually difficult to steal this size of module [11].

A village Ravana about $100 \mathrm{~km}$ from the capital city of state Raipur revealed immense satisfaction of the villagers. The positive outcomes of the electrification in the village is: increase in literacy and safety from wild animals. Prior to commissioning of solar PV lights wild animals like leopards would haunt this village and take away children but the illumination from solar power has scared 
wild animals. CREDA officials approached NMDC officials for their support to solar PV projects to provide basic power to villages, who readily agreed to share their CRS funds for electrification as it meets their social goals. The village is $100 \%$ household electricity connectivity and its improvement in the lives of the people is evident of the importance of electricity [3].

\section{Evaluation of Solar Photovoltaic In 17 Villages of Bijapur And Dantewada}

In this work, we have focused our studies only to the 17 villages of Bijapur (Mosla, Turnar, Chintanpalli, Dhanora, Gampur, Hiroli, Komla) and Dantewada (Japeli, Munga, Odsa, Pindumpal, Pinkonda, Rotad, Sadar, Tamodi, Tumla, Uspari). The reason behind choosing this villages is due to the fact that, these villages were electrified by solar Photovoltaic in the year of March 2017 by CREDA. Thus, analyzing the performance of these village will surely let us know the actual state of sustainable electricity state in the villages [3].
During the visit to the village, we asked set of questions to the villagers regarding the electrification. Figure 2 and Table 1 shows the list of villages surveyed for the study. In this study, we have contacted the local peoples of the villages to know the actual status and also collected data from the tehsil offices. Further in the villages Turnar, Komla, Sadar and Pinkonda are now connected to the grids. These villages have been connected to the grid and now $50 \%$ of the households are connected to the grid in merely 6-month time. From this field survey, we have found that the village electrification is someway hampered due to rural population not being aware about the opportunities near to them. In many places in the villages we have visited, we found that the electricity has not been connected to the households due to unawareness about the government subsidies. The interation with the villagers was very fruitfull and students were very encouraged by knowing about the potential of electricity to their lives. Thus, in these villages remote village electrification is very advantageous over the grid connectivity.

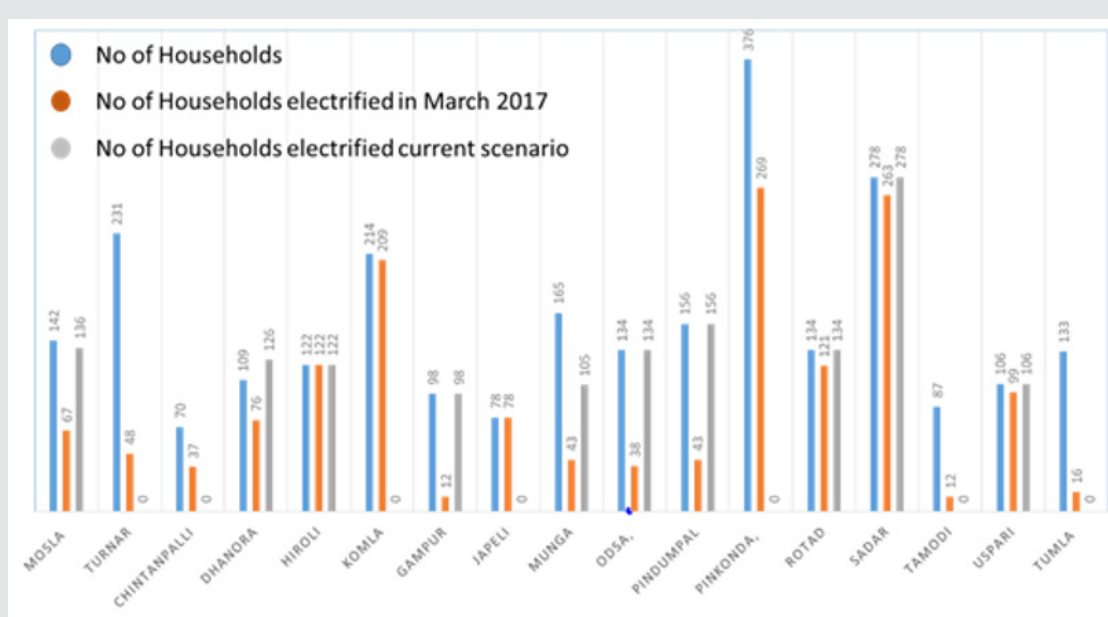

Figure 2: Status of villages electrified through Solar PV power.

Table 1: Status of villages electrified through Solar PV power.

\begin{tabular}{|c|c|c|c|c|}
\hline Village Name & No of House Holds & $\begin{array}{c}\text { No of Household } \\
\text { Connected to Solar PV }\end{array}$ & Current State & Remarks \\
\hline Mosla & 142 & 67 & 136 & $100 \%$ electrified through to pv \\
\hline Turnar & 231 & 48 & 0 & Grid connectivity \\
\hline Chintanpalli & 70 & 37 & Nil & Stolen or destroyed \\
\hline Dhanora & 109 & 76 & 126 & $100 \%$ electrified through to pv \\
\hline Hiroli & 122 & 122 & 122 & $100 \%$ electrified through to pv \\
\hline Komla & 214 & 209 & 0 & $100 \%$ electrified through to $\mathrm{pv}$ \\
\hline Gampur & 98 & 12 & 98 & $100 \%$ electrified through to $\mathrm{pv}$ \\
\hline Japeli & 78 & 78 & Nil & Stolen or destroyed \\
\hline Munga & 165 & 43 & 105 & Not electrified completely \\
\hline Odsa & 134 & 38 & 134 & Not electrified completely \\
\hline Pindumpal & 156 & 43 & 156 & Not electrified completely \\
\hline Pinkonda & 376 & 269 & 0 & Grid connectivity \\
\hline Rotad & 134 & 121 & 134 & $100 \%$ electrified through to $\mathrm{pv}$ \\
\hline
\end{tabular}




\begin{tabular}{|c|c|c|c|c|}
\hline Sadar & 278 & 263 & 278 & Grid connectivity \\
\hline Tamodi & 87 & 12 & Nil & Stolen or destroyed \\
\hline Uspari & 106 & 99 & 106 & $100 \%$ electrified through to pv \\
\hline Tumla & 133 & 16 & 0 & installation issues \\
\hline
\end{tabular}

\section{Nanomagnetic Fluid-Based Wind Energy Harvester}

Nanomagnetic fluid or Magnetic fluid (MF) -based wind energy power generation is novel invention which can efficiently converts input wind energy to electricity. This can be effectively used for the rural village electrification. Magnetic fluids are smart materials with unique properties which makes it very useful for many novel inventions such as sensing, thermal energy storage, EMI shielding, magnetic filters and dampers $[8,12]$. MFs are fascinating material and provides unique features which are utilized for the energy conversion device. MF based power generator is an energy conversion device which converts air thrust into an electrical energy. We have developed a portable electric power generator, consisting of a combination of permanent magnets, ferrofluid bearings and solenoid coils, which is capable of converting wind or mechanical energy into electrical energy in an efficient way [13, 14]. The concept of generation of electricity is based on the same Faraday's principle of electromagnetic induction. The incoming air rotates the fan blade, which further rotates the magnets which are connected via shaft. The design is made in such a way it is ergonomically compatible. Beneath the magnets, coils are placed. Magnets are dipped in MF thereby forming bearing which assists the relative motion between magnets and coil. Coils and ferrofluid bearing are separated by a thin non-porous sheet. The small portable setup on the rooftop can generate more than 100 watt of power which at low wind speed of $4 \mathrm{~m} / \mathrm{s}$ due to low frictional properties of the MF which is the major advantage of the present system.

\section{Conclusion}

In this work, we have surveyed the rural electrification scenario of the state Chhattisgarh remote villages. We have focused my study limited to the 17 villages in the area Bijapur and Dantewada which are connected to the electricity through off grid systems. The efficient use to SHS and microgrids in the remote villages of Chhattisgarh has shown excellent potential and proving to be a reliable power supply option. The most prominent way to achieve $100 \%$ electrification is through off grid power supply. Alternatively, wind energy can be an efficient solution in these areas. Wind energy is much cheaper than but the only drawback with wind turbines is that they require high average wind speeds, we have proposed the novel system to deal with this problem. Magnetic fluid-based power generators have the ability to work with low wind speed also which makes it an efficient solution for the current needs.

\section{References}

1. Zahnd A, Kimber HM (2009) Benefits from a renewable energy village electrification system. Renewable Energy 34(2): 362-368.

2. Gmünder SM (2010) Life cycle assessment of village electrification based on straight jatropha oil in Chhattisgarh, India. Biomass and Bioenergy 34(3): 347-355.

3. Millinger M, Mårlind T, Ahlgren EO (2012) Evaluation of Indian rural solar electrification: A case study in Chhattisgarh. Energy for Sustainable Development 16(4): 486-492.

4. Noorjahan (2018) Dipolar Interaction and Magneto-Viscoelasticity in Nanomagnetic Fluid. Journal of Nanoscience and Nanotechnology 18(4): 2746-2751.

5. Mishra A (2019) Measurement of Static and Dynamic MagnetoViscoelasticity in Facile Varying pH Synthesized CoFe204-Based Magnetic Fluid. IEEE Transactions on Magnetics 55(12): 1-7.

6. Jahan N (2017) Enchancment in viscoelastic properties of flake-shaped iron based magnetorheological fluid using ferrofluid. Colloids and Surfaces A: Physicochemical and Engineering Aspects 529: 88-94.

7. Pathak S (2017) Magnetic Fluid Based High Precision Temperature Sensor. IEEE Sensors Journalm 17(9): 2670-2675.

8. Pathak S (2019) Improved thermal performance of annular fin-shell tube storage system using magnetic fluid. Applied Energy 239: 15241535.

9. Jain K (2019) Dynamic magneto-optical inversion in magnetic fluid using NanoMOKE. Journal of Magnetism and Magnetic Materials 475: 782-786.

10. Palit D, Sarangi GK, Krithika PR (2014) Energising Rural India Using Distributed Generation: The Case of Solar Mini-Grids in Chhattisgarh State India in Mini-Grids for Rural Electrification of Developing Countries: Analysis and Case Studies from South Asia. In: Bhattacharyya SC(Eds.) and Palit D(Eds.) Springer International Publishing: Cham pp. 313-342.

11. Jain M, Mital M, Syal M (2016) Rural Electrification through Solar Energy: Insights from Chattisgarh State of India. International Journal of Environment and Sustainability [IJES] 5(2): 99-104.

12. Noorjahan (2018) Improved magneto-viscoelasticity of cross-linked PVA hydrogels using magnetic nanoparticles. Colloids and Surfaces A: Physicochemical and Engineering Aspects 539: 273-279.

13. Jain K, Pathak S, Pant RP (2016) Enhanced magnetic properties in ordered oriented ferrofibres. RSC Advances 6(75): 70943-70946.

14. Singh A (2020) Tuning the magnetocrystalline anisotropy and spin dynamics in CoxZn1-xFe2O4 $(0 \leq x \leq 1)$ nanoferrites. Journal of Magnetism and Magnetic Materials 493: 165737 
(C) Comons Attribution 4.0 License

To Submit Your Article Click Here: Submit Article

DOI: 10.32474/ARME.2020.02.000142

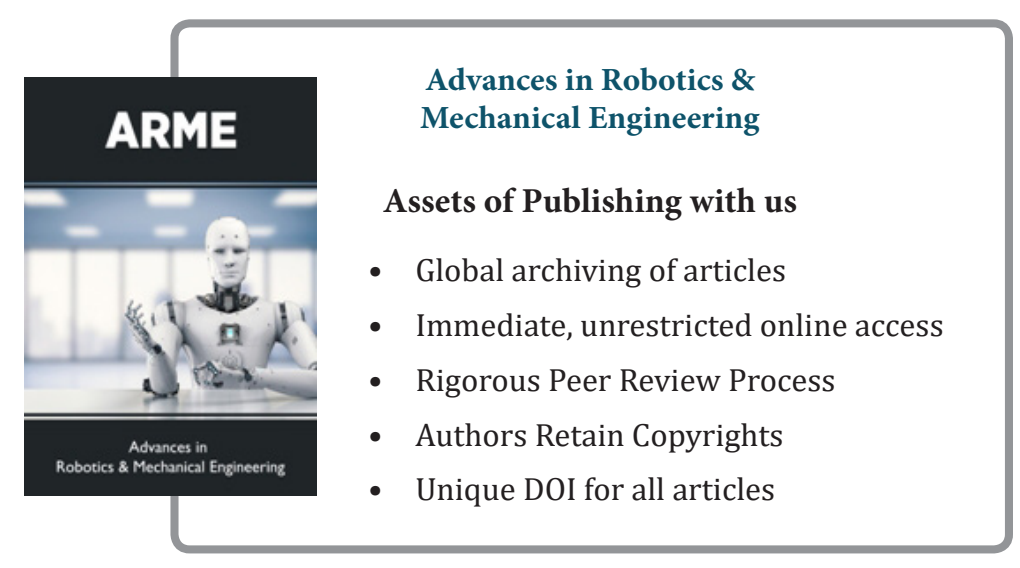

